WS5-P01

\title{
3D Seismic Survey in Crystalline Rocks of
} Saxony, Germany

\author{
E. Lueschen* (Leibniz Institute for Applied Geophysics (LIAG)), F. Rost \\ (DMT-Petrologic), G. Hoecht (DMT-Petrologic) \& R. Thomas (Leibniz \\ Institute for Applied Geophysics)
}

\section{SUMMARY}

3D seismic measurements have been performed in 2012 to explore a petrothermal reservoir in a crystalline environment (granite intrusion, metamorphic cover) within the Erzgebirge in Saxony. The intention and challenge is to image and characterize a steeply dipping fault zone with potentially permeable fracture zones at target depths of 5-6 km and temperatures well above $150{ }^{\circ} \mathrm{C}$. The vibroseis technique was used in the experiment. A suite of imaging methods has been applied, from conventional CMP-stacking, CRS processing to pre-stack migrations. 


\section{Amsterdam '14}

\section{Introduction}

In Germany, the exploration of hydrothermal reservoirs by 3D seismic measurements is common practice in sedimentary environments in the Bavarian Molasse Basin and in the Upper Rhine Graben since about 5 years. Such exercise has been performed now in granites and outcropping crystalline rocks of the western Erzgebirge in Saxony (Fig. 1) within the Gera-Jachymov-Fault Zone. Its aim is to image and characterize steeply dipping fault and fracture zones for their hydraulic permeability. Target depth is 5-6 km within a granite pluton where temperatures above $150{ }^{\circ} \mathrm{C}$ are expected. Such petrothermal reservoirs hold a much higher geothermal potential in Germany than known from hydrothermal reservoirs. While the latter contain hot water already, particularly the limestone aquifer in the Bavarian Molasse Basin, petrothermal reservoirs are characterized by the storage of dry heat at depth where cold water needs to be injected first.

A feasibility study of the research group "Deep Geothermal Resources of Saxony" (LfULG Sachsen, 2011) suggested the area Aue-Bad Schlema-Schneeberg to be qualified for a deep petrothermal project, mainly based upon favorable temperature conditions and the huge amount of knowledge available from mining activities above the top of granite bodies. The Leibniz Institute for Applied Geophysics (LIAG, Hannover) undertook the task of exploring potential fracture zones within the granite pluton. The seismic measurements were performed using the vibroseis technique between August and November 2012.

\section{D Seismic Survey}

The 3D reflection seismic experiment consisted of source and receiver lines with nominally $400 \mathrm{~m}$ spacing and $30 \mathrm{~m}$ point spacing within an area of $10 \mathrm{~km} \times 12 \mathrm{~km}$ size. Three heavy vibrators of $27 \mathrm{t}$ each were used as seismic source with a $12-96 \mathrm{~Hz}$ sweep signal of $10 \mathrm{~s}$ length, 8 -fold stacked. The recording time after vibroseis correlation was $6 \mathrm{~s}$ with a sampling interval of $2 \mathrm{~ms}$. A patch of max. 6000 recording channels was moved in role-along mode over the area of totally 8146 recording stations consisting of 12 geophones each. There were 5348 vibrator points, resulting in a nominal common-midpoint (CMP-) coverage of up to 250 in the centre of the area for bin sizes of $15 \mathrm{~m} \times 15$ $\mathrm{m}$. In the CMP domain, the traces are distributed irregularly over all azimuths for offsets up to 6000 $\mathrm{m}$.

\section{Processing}

First promising images even after brute processing in the field showed a great number of reflecting structures within the granite pluton in the target zone which are of particular interest for a petrothermal project and which demand a further characterization and explanation. First conventional CMP-processing was done at the LIAG with further encouraging results. The pre-processing turned out to be of eminent importance, such as noise-editing, field statics (from short-refraction surveys), refraction statics (from first arrivals of the vibroseis production), residual statics and surfaceconsistent amplitude scaling and deconvolution. All these steps were continuously upgraded. Common-reflection-surface (CRS) processing (e.g. Jäger et al., 2001) was used to produce zero offset stacks and enhanced pre-stack gathers. In CRS processing, we considered azimuth-dependent stacking velocities which could better focus several events in comparison to the use of a single stacking velocity field. Finally, post-stack and pre-stack time migrations were applied.

\section{Conclusions}

The 3D seismic reflection technique has been proven as an indispensable tool for geothermal exploration even in a crystalline environment. A rich repertoire of structures within the granite pluton has been imaged. Further analyses for interpretation of their nature are necessary and possible in order to define an optimum drill path for a research well which is considered as the next stage for a possible geothermal plant. 


\section{Amsterdam ' 14}

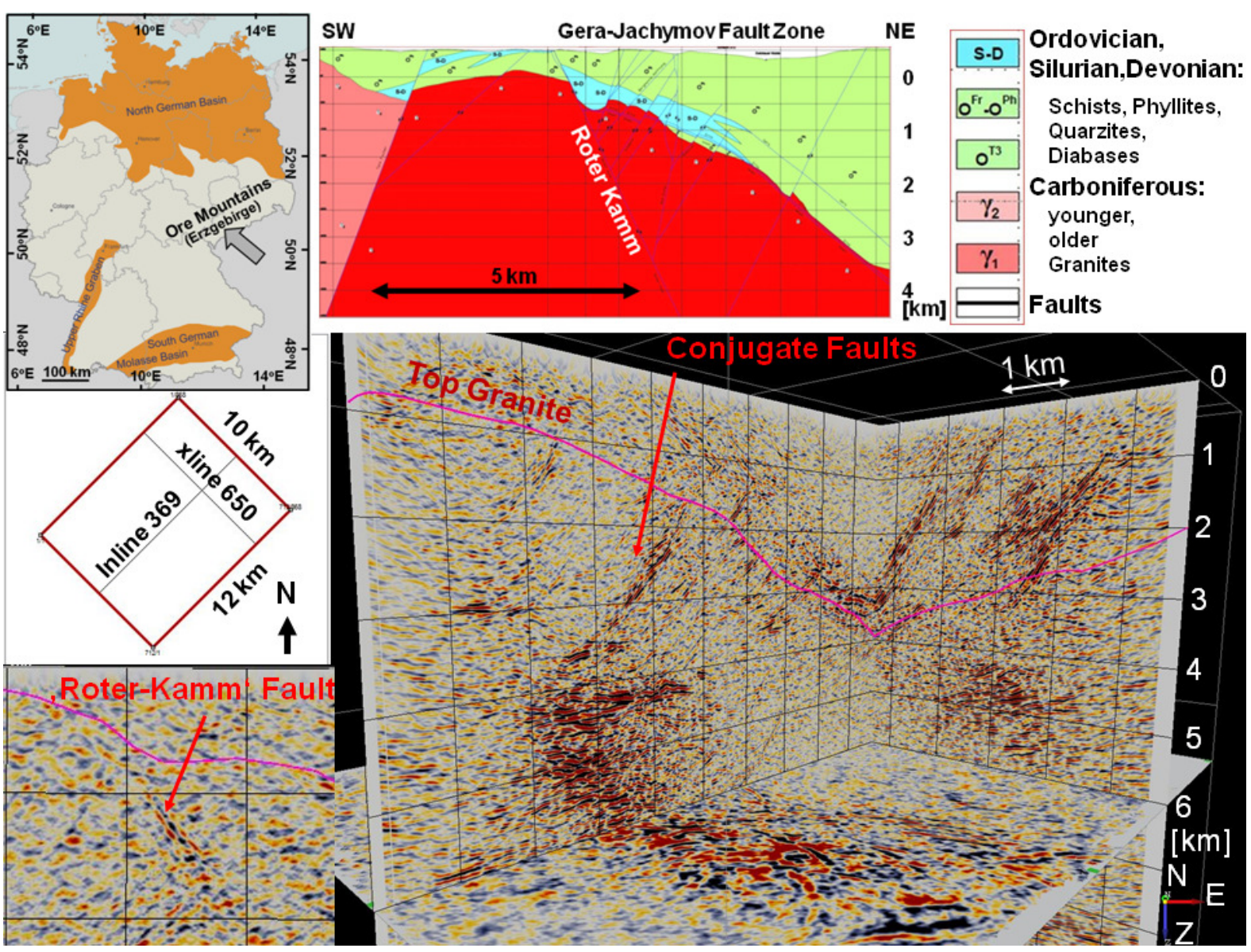

Figure 1 Vertical sections and depth slice through the data volume after CRS-stacking and FD migration (inline 369, SW-NE, crossline 650, NW-SE according to the base map middle left). Red line marks top of granite according to detailed information from mining. Note numerous structures within the granite pluton, particularly the steeply $S W$ dipping conjugate fault zones. Structures above the top of the granite were prospective for uranium mining. Bottom left: Zoom of inline 467 imaging the 'Roter-Kamm' normal fault. Upper right: Simplified vertical section through the study area according to a feasibility study (WISMUT, 2009, unpublished report, LfULG Sachsen, 2011). The 'Roter Kamm' with a throw of about $500 \mathrm{~m}$ and its conjugate fault zones are extrapolated from the overburden into the granite body and are therefore topic for better seismic imaging. The overburden (blue, green) including the faults inside are precisely known from uranium mining down to max. $1.5 \mathrm{~km}$ depth. Mining, however, stopped at the top of the granite. Upper left: Index map showing areas for hydrothermal usage (coloured, http://www.geotis.de) and location of the study area (arrow).

\section{Acknowledgements}

Funding by the Federal Ministry of Environment, Nature Conservation and Nuclear Safety (BMU) of Germany under the funding no. 0325363A is gratefully acknowledged.

\section{References}

Jäger, R., Mann, J., Höcht, G. and Hubral, P. [2001] Common-reflection-surface stack: Image and attributes, Geophysics, 66, 97-109.

LfULG Sachsen [2011] Forschungsbericht Tiefengeothermie Sachsen, Schriftenreihe des LfULG, Heft 9/2011, 127 p., appendices, Landesamt für Umwelt, Landwirtschaft und Geologie, Freistaat Sachsen. 